Journal of Engineering and Applied Sciences 15 (3): 876-880, 2020

ISSN: 1816-949X

(C) Medwell Journals, 2020

\title{
An Experiment of Markov Chain and N-Gram Methods for Reconstructing a Music
}

\author{
Yosua Giovanni Pratama Polii, Tito Waluyo Purboyo and Randy Erfa Saputra \\ Faculty of Electrical Engineering, Telkom University, Bandung, Indonesia
}

\begin{abstract}
Music is an art that relies on intuition and creativity to make music. Making a musical composition is an ordinary work done by a musician. Now a days, an algorithm can make a composition of music based on an existing song. Making music using an algorithm is a little difficult because it requires knowledge of music and programming logic. Some people have made programs to generate music from an algorithm. The Markov chain method is one method for making music. Therefore, this study will review one music reconstruction that has been made.
\end{abstract}

Key words: Markov Model, music, composition, intuition, reconstruction, programming logic

\section{INTRODUCTION}

Technological development is very fast until almost all human activities are related to technology (Dewi et al., 2016). Anyone can easily access and even create a work using technology (Oktavianto et al., 2017). The process of making music this time can be done without a real instrument. However, music still depends on human creativity to produce it. This time, we try to learn to make melodies followed by probability and reconstruct that melodies from an existing song.

The composition algorithm approach mostly uses fractals and l-systems (Plans and Morelli, 2012). This approach collaborated with several methods that have similar work methods (Suprem and Ruprem, 2013). Markov chain was a popular method in the early years of algorithmic composition. The aim is to produce a new melody of music from different music genre and review the results. Markov chain is used to determine the possibility of note to be generated using transition probability values.

From this review, we can produce our own music. Make music from zero compositions to become whole music requires a lot of time, production cost and require people who are capable of playing and processing theses compositions.

\section{MATERIALS AND METHODS}

In this study review, we discuss and assess song results from the Markov chain process.

Markov chain: Markov chain is also known to be used to produce music. Markov method is one stochastic method for analyzing and learning from a dataset
(Jame and Michael, 1994). This method analyzes the data from the data set and produces an optimal matrix for each situation and maximizes the best results that are used as the values set for the transition in the generation of music (Qi et al., 2007). To determine the next state, the Markov chain uses Eq. 1 (Hassani and Wuryandari, 2016):

$$
\begin{aligned}
& \mathrm{P}\left(\mathrm{X}\left(\mathrm{t}_{\mathrm{k}+1}\right)=\mathrm{x}_{\mathrm{k}+1} \mid \mathrm{X}\left(\mathrm{t}_{\mathrm{k}}\right)=\mathrm{x}_{\mathrm{k}}, \ldots, \mathrm{X}\left(\mathrm{t}_{1}\right)=\mathrm{x}_{1}\right)= \\
& \mathrm{P}\left(\mathrm{X}\left(\mathrm{t}_{\mathrm{k} 1}\right)=\mathrm{x}_{\mathrm{k}+1} \mid \mathrm{X}\left(\mathrm{t}_{\mathrm{k}}\right)=\mathrm{x}_{\mathrm{k}}\right.
\end{aligned}
$$

Where:

$$
\begin{array}{lll}
\mathrm{P} & : & \text { Probability } \\
\sqrt{\mathrm{x}_{\mathrm{k}}} & : \text { Current state } \\
\sqrt{\mathrm{x}_{\mathrm{k}+1}} & : & \text { Next state } \\
\mathrm{k} & : & \text { State } \\
\mathrm{t} & : & \text { Time }
\end{array}
$$

To determine the next step, its requires a transition probability value between note. Transition probability is the probability value from a state to another in the next period. Transition probability use Eq. 2 (Hassani and Wuryandari, 2016):

$$
P i j=P\left(X_{t+1}=j \mid X_{t}=i\right)
$$

Where:

Pij : Transition probability from state i to $\mathrm{j}$

$\begin{array}{lll}\mathrm{i} & : \text { Current state } \\ \mathrm{j} & : \text { Next state } \\ \mathrm{n} & : \text { State } \\ \mathrm{t} & : \text { Time } \\ \mathrm{X}_{\mathrm{t}} & : \text { Current state } \\ \mathrm{X}_{\mathrm{t}+1} & : \text { Next state }\end{array}$ 
n-gram: $n$-gram is a collection of words or character with each length $n$ words. The implementation of n-gram in an application can be developed for spelling correction, word breaking and text summarization.

n-gram will take a number of words or state (state) that we need from a sentence. Like the phrase "MOBIL" then for n-gram the sentence is:

- Unigram: M, O, B, I, L

- Bigram: MO, OB, BI, IL

- Trigram: MOB, OBI, BIL

MIDI file: To analyze the whole song, the song must be able to be put together in the form of a file, so that, it can be read by the system to be randomized automatically (Ramanto and Maulidevi, 2017). MIDI file is a file format that is suitable for use because it has been known to many people. This file becomes the input data used on the system. Almost all electronic musical instruments, manufacturers, make devices that can read and/or write MIDI data.

MIDI file is a music file that contains many instructions for managing a tone notation and is nothing more than a music protocol. MIDI files do not contain audio as audio produced from a synthesizer. MIDI provides commands that are used as data to synth to produce sound (Saputra and Prihatmanto, 2012).

MIDI files have many elements that regulate a tone, tone duration, pitch, modulation, velocity and much more. The whole system uses the Markov chain method by using the transition probability of the overall note to reconstruct new songs. MIDI files do not contain audio as audio produced from a synthesizer. MIDI provides commands that are used as data to synth to produce sound (Saputra and Prihatmanto, 2012).

Note element: Most Markov chain methods are to produce a new song with a new set of notes. So, every note transition will be made a probability value. Each transition probability value will be made on a matrix to represent the transition probability value. To be more clearly seen in the calculation below. From Fig. 1, the note sequence is E-G-A-C-C-F-G-F-C, so, the transition probability matrix can be made in Table 1 .

Musical composition is generally limited to probability and statistics (Merwe and Schulze, 2010). There are several studies on the use of algorithms in music composition (Jame and Michael, 1994). The method used in this study is to analyze input data statistically note-to-note probability.

Note duration element: In some experiment, the note length is also used as a parameter. If input note sequence

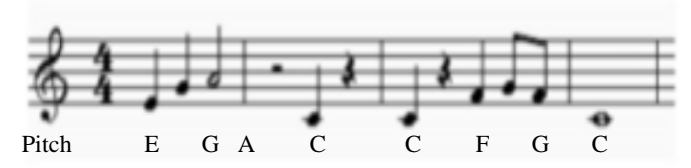

Fig. 1: Example of a music notation (Hassani and Wuryandari, 2016)

Table 1: Note transition probability matrix (Hassani and Wuryandari,

\begin{tabular}{lrrrrr}
\multicolumn{2}{c}{ 2016) } & \multicolumn{1}{c}{ F } & G & A \\
\hline Notations & C & E & \multicolumn{1}{c}{ F } & 0 & 0 \\
C & 0.5 & 0 & 0.5 & 1 & 0 \\
E & 0 & 0 & 0 & 0.5 & 0 \\
F & 0.5 & 0 & 0 & 0 & 0.5 \\
G & 0 & 0 & 0.5 & 0 & 0 \\
A & 1 & 0 & 0 & &
\end{tabular}

Table 2: Duration transition probability matrix (Saputra and Prihatmanto, 2012)

\begin{tabular}{lcccc}
\hline Input & $1 / 8$ & $1 / 4$ & $1 / 2$ & 1 \\
\hline 0 & 0.00 & 1.00 & 0.00 & 0.00 \\
$\sqrt{1 / 8}$ & 0.25 & 0.00 & 0.00 & 0.25 \\
$1 / 4$ & 0.25 & 0.75 & 0.25 & 0.00 \\
$1 / 2$ & 0.00 & 1.00 & 0.00 & 0.00 \\
\hline
\end{tabular}

is $1 / 4-1 / 4-1 / 2-1 / 4-1 / 4-1 / 4-1 / 8-1 / 8-1$, calculation results using the transition probability matrix can be seen in Table 1 (Hassani and Wuryandari, 2016).

From Table 2, the transition probability value of the duration of a note is obtained. The value in the table is a transition from the note length of a sequence of input note lengths. For examples, the value of $1 / 4-1 / 8$ is 0.25 . The note length of the transition probability value in Table 2 , will be used by the system to begin reconstructing with the Markov chain method.

Process: The first thing to do is read the contents of the MIDI file to find out the MIDI number and the duration of the tone. After all elements are seen, then take the tone number and duration of the tone (Fig. 2).

Figure 3 is a MIDI number from a MIDI file that will be processed. MIDI numbers will be processed with n-gram and Markov chain. Figure 4 is a MIDI duration index of a MIDI file that will be processed and MIDI duration is only processed by the Markov chain.

From Fig. 5 in the ngram process, the MIDI number will be combined with the tone number after it becomes one inde. After becoming a new index, then look for probabilities to the next tone of the index. From Fig. 6, each index has the next MIDI number. Besides MIDI numbers, the duration index is also processed to find probabilities to the next duration index.

From Fig. 7, the duration of MIDI is in units of seconds and you can see the duration of the duration 


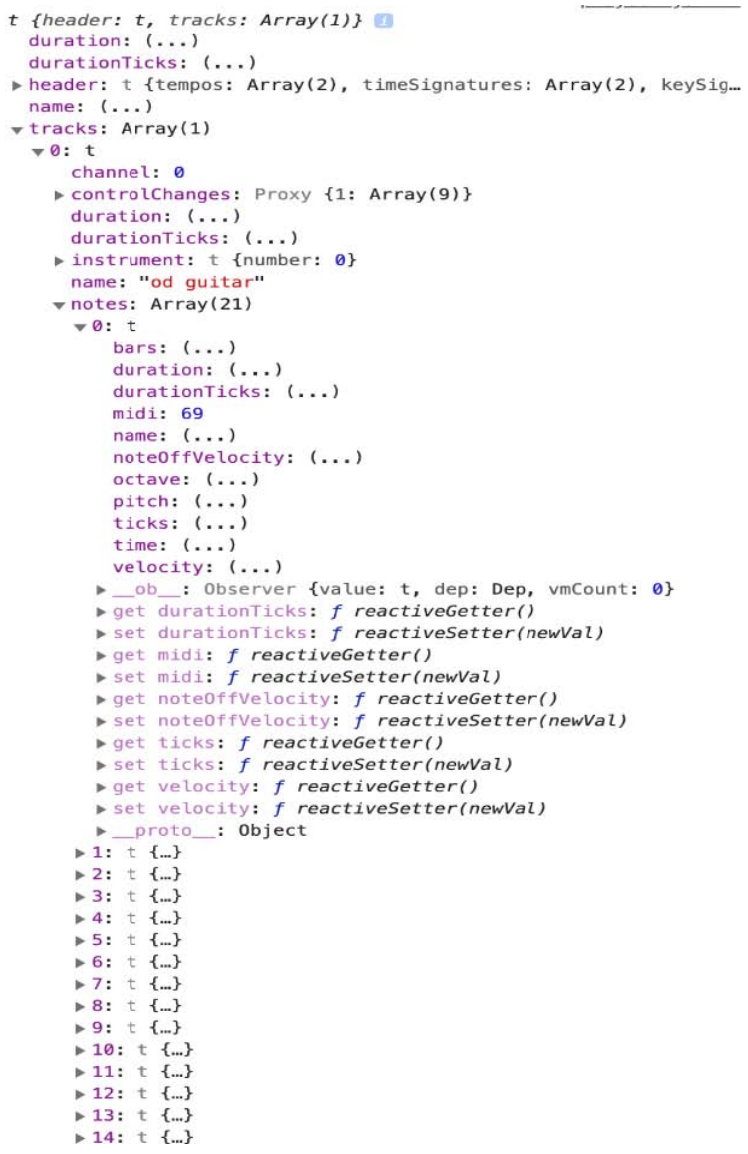

Fig. 2: Extraction of file mid

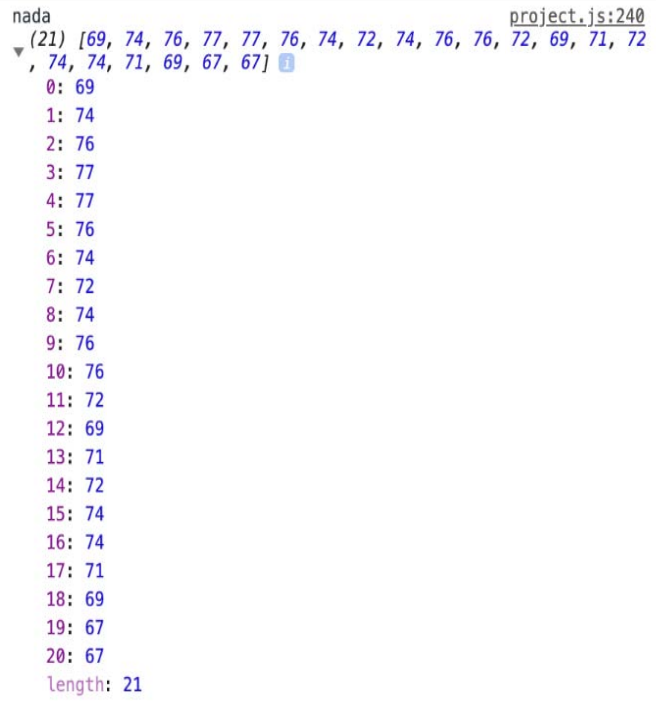

Fig. 3: Sequence of MIDI number

index from the previous index duration. The last process is to produce a new tone with a predetermined

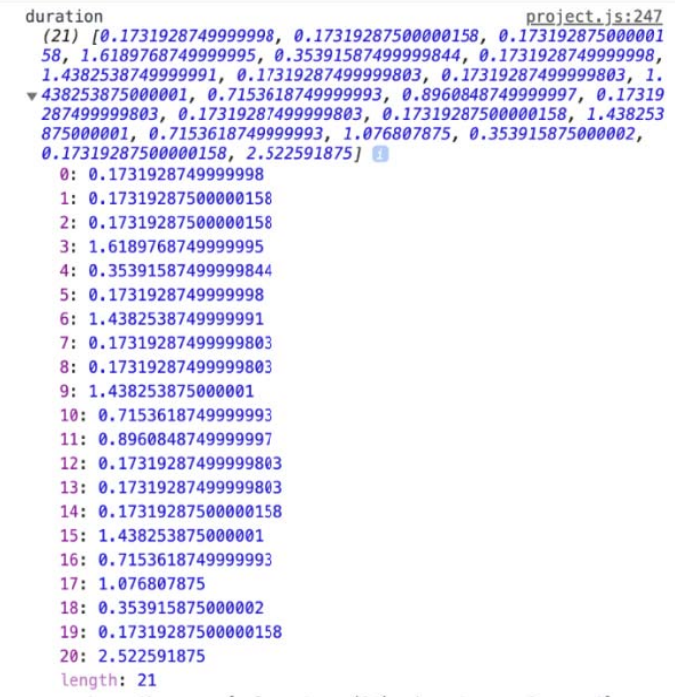

Fig. 4: Sequence of MIDI duration

duration based on the probability that is owned. Each new tone produced from two tones in the index, then the last 


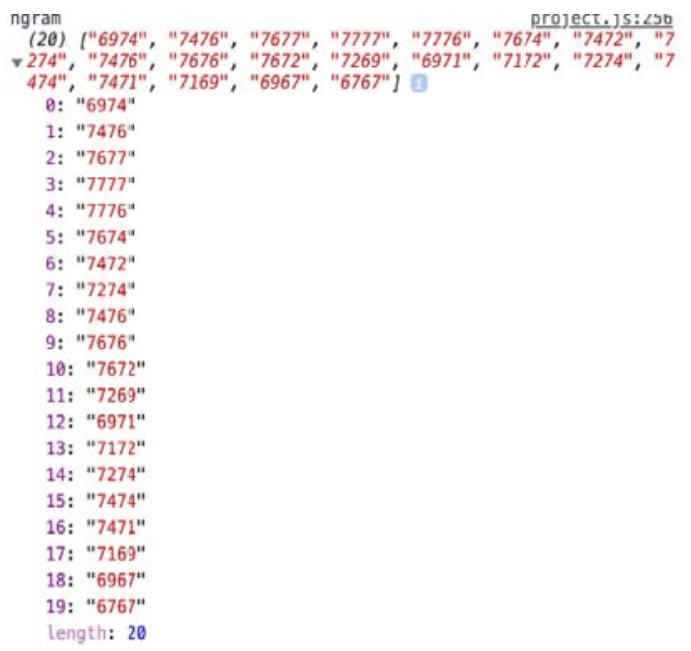

Fig. 5: New index from merging 2 MIDI numbers

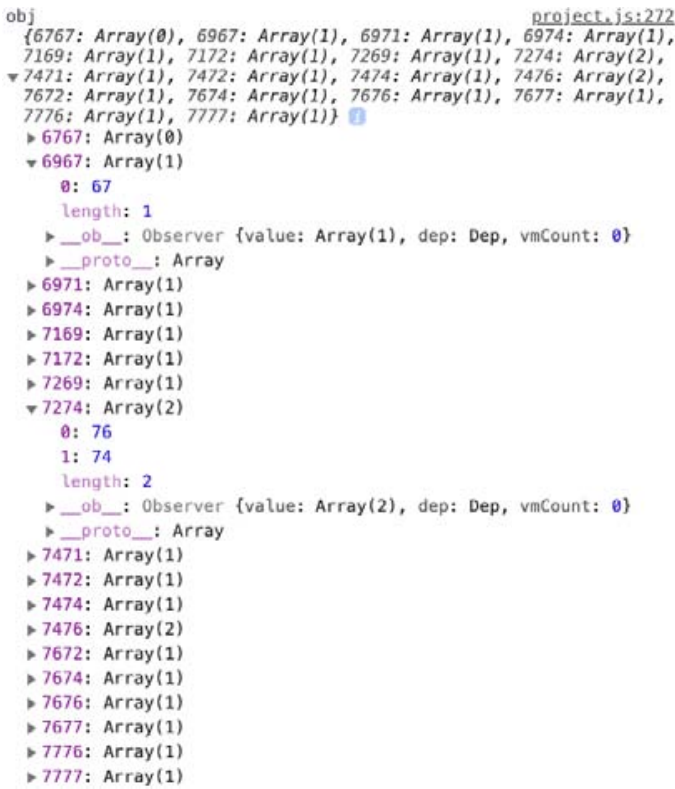

Fig. 6: Probability index to the next MIDI number

note in the index is combined with a new tone to look for the next tone based on the probability value of the newly joined index.

This is why the $\mathrm{N}$-value of the n-gram process is only limited to $\mathrm{N}=2$. If $\mathrm{N}$ is more than two, there is a possibility that one song does not have a repetition of a combination of several notes that will produce a possibility that is almost always $100 \%$ and the song produced is the same as the original song. Figure 8 is the result where each MIDI number is paired with the MIDI duration before the MIDI file is generated.
[6767: Array(0), 6967: Array(1), 6971: Array(1), 6974: Array(1) 7169: Array(1), 7172: Array(1), 7269: Array(1), 7274: Array(2), 17471: Array(1), 7472: Array(1), 7474: Array(1), 7476: Array(2), 7672: Array(1), 7674: Array(1), 7676: Array(1), 7677: Array(1),

10.1731928749999998: Array(2), 0.17319287500000158: Arraject.js:28 6189768749999995: Array(1), 0.35391587499999844: Array(1), 1.43 2538749999991: Array(1), ..] [ ह

b. 353915875000002: [0.17319287500000158]

0.1731928749999998: Array(2)

0: 0.17319287500000158

1: 1.4382538749999991

length: 2

- proto : Array(0)

0.7153618749999993: (2) [0.89608487499999997, 1.076807875]

- 0.8960848749999997: [0.17319287499999803]

- 0.17319287499999803 : (4) [0.17319287499999803, 1.438253875000

-0.17319287500000158: Array(4)

$0: 0.17319287500000158$

1: 1.6189768749999995

2: 1.438253875000001

3: 2.522591875

length: 4

- proto : Array(0)

$\rightarrow 0.35391587499999844:[0.1731928749999998]$

1. 1.076807875 : [0.353915875000002]

- 1.438253875000001: (2) [0.7153618749999993, 0.715361874999999

$\rightarrow 1.4382538749999991$ : [0.17319287499999803]

1.6189768749999995: [0. 35391587499999844]

2.522591875: [1

length: 0

Fig. 7: Probability index of duration to the next duration index

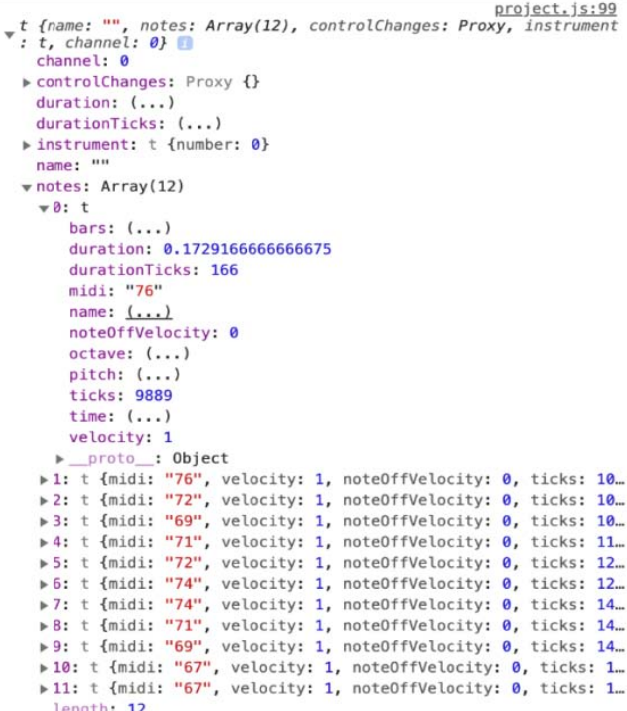

Fig. 8: The result of merging the MIDI number with the duration index

\section{RESULTS AND DISCUSSION}

Because music is subjective, the best way to assess the results of this method is by survey. The source of the song to be used is divided by genre and music scale. The results of several songs produced can be seen in Table 3. 
Table 3: Result

\begin{tabular}{lccc}
\hline Songs & Musicality & Efficiency & Pattern \\
\hline Ibu Kita Kartini (Vocal) & 8 & 6 & 8 \\
Kill this love & 8 & 7 & 7 \\
Gundul-Gundul Pacul (Vocal) & 7 & 8 & 7 \\
Spain Chick Corea & 8 & 7 & 9 \\
Manuk Dadali (Vocal) & 7 & 6 & 7 \\
Es lilin (Vocal) & 6 & 6 & 7 \\
$\Sigma$ total & 7,333 & 6,667 & 7,5 \\
\hline
\end{tabular}

\section{CONCLUSION}

After hearing the results of the song and seeing the assessment of the experiment, for types of songs such as pop and traditional songs will produce a new one that sounds neat and delicious. This is because the tone scale used is simple and easy to hear. Whereas types of songs such as jazz which have complicated types of notes will produce songs that sound less pleasant and like contemporary songs.

\section{RECOMMENDATION}

For the future work, the Markov chain model can collaborate with other methods that can improve the result of a song's reconstruction.

\section{REFERENCES}

Dewi, A.K., A. Novianty and T.W. Purboyo, 2016. Stomach disorder detection through the iris image using backpropagation neural network. Proceedings of the 2016 International Conference on Informatics and Computing (ICIC), October 28-29, 2016, IEEE, Mataram, Indonesia, ISBN: 978-1-50901649-5, pp: 192-197.

Hassani, Z. and A.I. Wuryandari, 2016. Music generator with markov chain: A case study with beatme touchdown. Proceedings of the 2016 6th International Conference on System Engineering and Technology (ICSET'16), October 3-4, 2016, IEEE, Bandung, Indonesia, pp: 179-183.
Jame, W. and T. Michael, 1994. A markov chain model for statistical software testing. IEEE Trans. Software Eng., 20: 812-824.

Merwe, A.V.D. and W. Schulze, 2010. Music generation with Markov models. IEEE. Multimedia, 18: 78-85.

Oktavianto, B., T.W. Purboyo and R.E. Saputra, 2017. A proposed method for secure steganography on PNG image using spread spectrum method and modified encryption. Intl. J. Appl. Eng. Res., 12: 10570-10576.

Plans, D. and D. Morelli, 2012. Experience-driven procedural music generation for games. IEEE. Trans. Comput. Intell. AI. Games, 4: 192198.

Qi, Y., J.W. Paisley and L. Carin, 2007. Music analysis using hidden Markov mixture models. IEEE. Trans. Signal Process., 55: 5209-5224.

Ramanto, A.S. and N.U. Maulidevi, 2017. Markov chain based procedural music generator with user chosen mood compatibility. Int. J. Asia Digital Art Des. Assoc., 21: 19-24.

Saputra, R.E. and A.S. Prihatmanto, 2012. Design and implementation of beatme as a Networked Music Performance (NMP) system. Proceedings of the 2012 International Conference on System Engineering and Technology (ICSET'12), September 11-12, 2012, IEEE, Bandung, Indonesia, pp: 1-6.

Suprem, A. and M. Ruprem, 2013. A new composition algorithm for automatic generation of thematic music from the existing music pieces. Proceedings of the World Congress on Engineering and Computer Science VOl. 2 (WCECS'13), October, 23-25, 2013, San Francisco, California, USA., pp: 1-5. 